Supplement of Atmos. Chem. Phys., 15, 13957-13971, 2015

http://www.atmos-chem-phys.net/15/13957/2015/

doi:10.5194/acp-15-13957-2015-supplement

(C) Author(s) 2015. CC Attribution 3.0 License.

(c) (i)

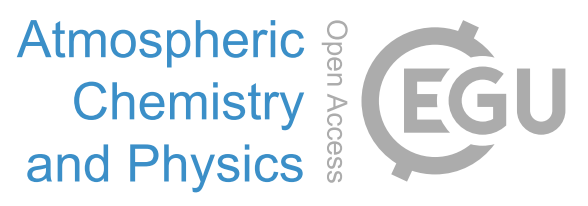

Supplement of

\title{
Seasonal variation of ozone and black carbon observed at Paknajol, an urban site in the Kathmandu Valley, Nepal
}

D. Putero et al.

Correspondence to: D. Putero (d.putero@isac.cnr.it)

The copyright of individual parts of the supplement might differ from the CC-BY 3.0 licence. 
Table S1. Correlation coefficients $(r)$ between several parameters $\left(\mathrm{BC}, \mathrm{O}_{3}\right.$, accumulation and coarse particles, WS, T and RAD) for hourly and daily (in parentheses) values, over the whole sampling period, computed during convective hours only (i.e. between 11:00 and 17:00).

\begin{tabular}{cccccccc}
\hline & $\mathrm{O}_{3}$ & $\mathrm{BC}$ & Acc. & Coarse & WS & $\mathrm{T}$ & RAD \\
\hline $\mathrm{O}_{3}$ & - & $0.20(0.17)$ & $0.62(0.61)$ & $0.51(0.52)$ & $0.16(0.49)$ & $0.18(0.16)$ & $0.50(0.53)$ \\
$\mathrm{BC}$ & $0.20(0.17)$ & - & $0.82(0.81)$ & $0.79(0.71)$ & $-0.35(-0.24)$ & $-0.44(-0.58)$ & $-0.10(-0.36)$ \\
$\mathrm{Acc}$. & $0.62(0.61)$ & $0.82(0.81)$ & - & $0.79(0.79)$ & $-0.03(0.15)$ & $-0.13(-0.13)$ & $0.03(-0.01)$ \\
Coarse & $0.51(0.52)$ & $0.79(0.71)$ & $0.79(0.79)$ & - & $-0.06(0.21)$ & $-0.03(0.03)$ & $0.03(0.04)$ \\
$\mathrm{WS}$ & $0.16(0.49)$ & $-0.35(-0.24)$ & $-0.03(0.15)$ & $-0.06(0.21)$ & - & $0.28(0.37)$ & $0.11(0.72)$ \\
$\mathrm{T}$ & $0.18(0.16)$ & $-0.44(-0.58)$ & $-0.13(-0.13)$ & $-0.03(0.03)$ & $0.28(0.37)$ & - & $0.34(0.50)$ \\
$\mathrm{RAD}$ & $0.50(0.53)$ & $-0.10(-0.36)$ & $0.03(-0.01)$ & $0.03(0.04)$ & $0.11(0.72)$ & $0.34(0.50)$ & - \\
\hline
\end{tabular}

a

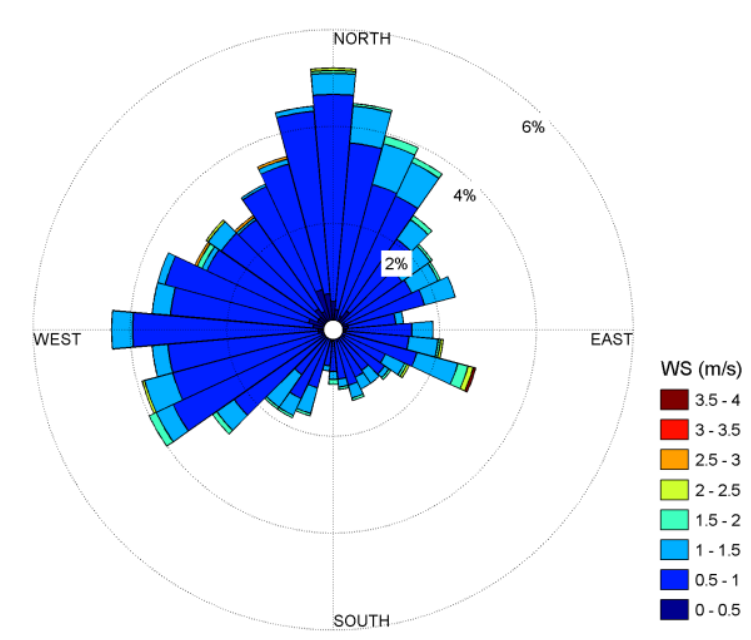

b Winds between 12 and $16 \mathrm{LT}$

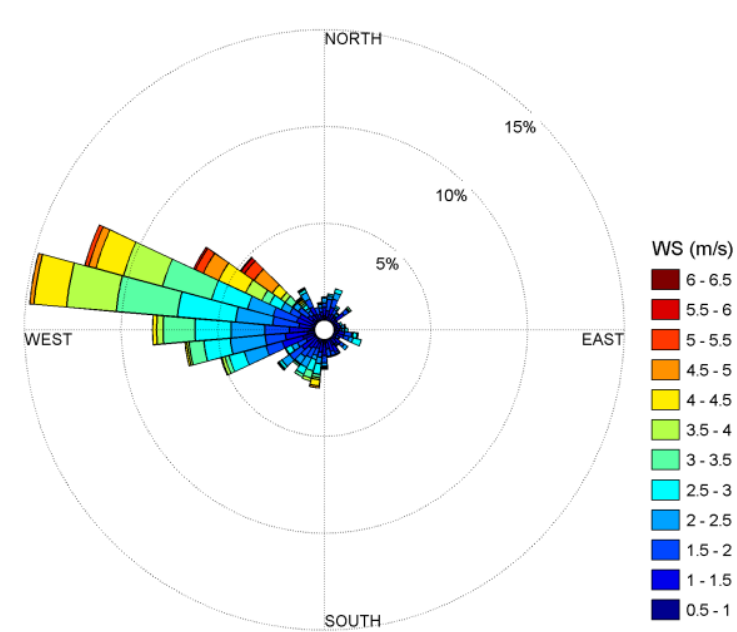

Figure S1. Wind direction and intensities for Paknajol. Panel a shows winds between 0:00 and 4:00, while panel $b$ encloses winds between 12:00 and 16:00. 

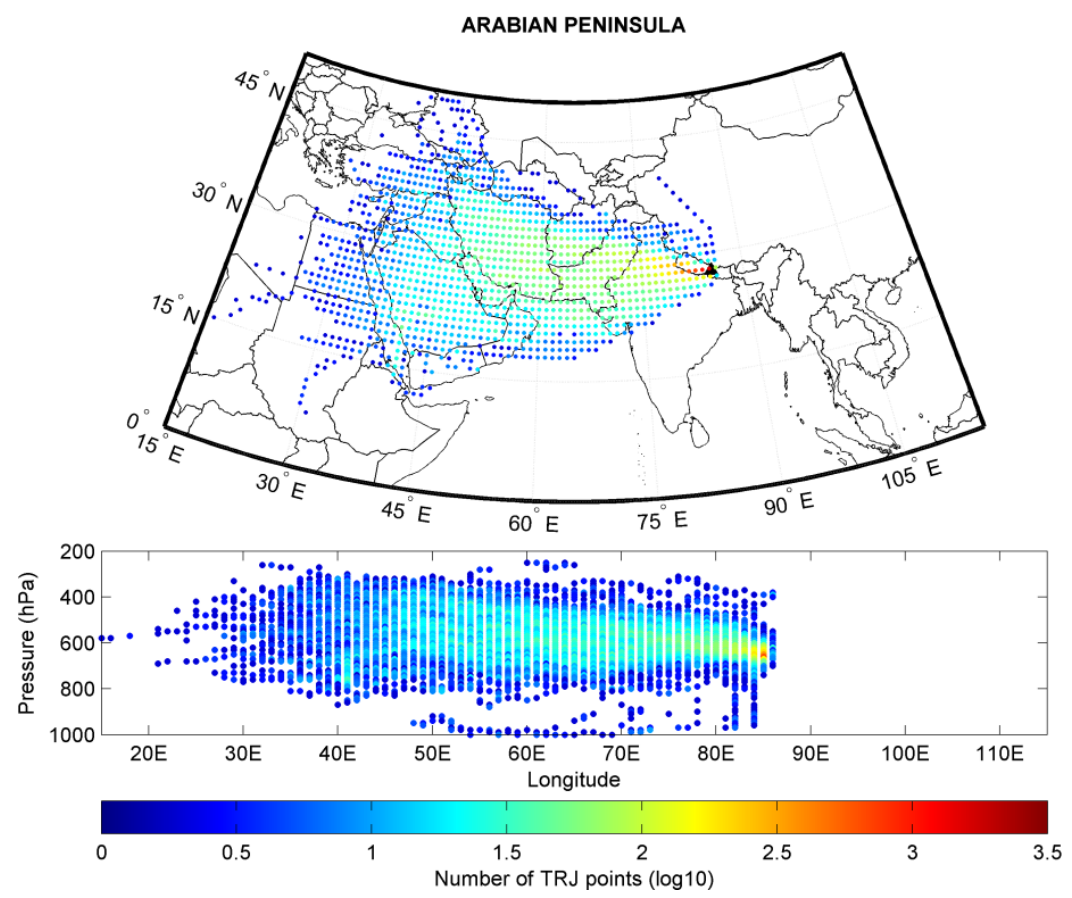

Figure S2. Concentration field (vertical cross section included) for HYSPLIT back-trajectory points ending at Paknajol, belonging to the Arabian Peninsula cluster. Trajectory points have been aggregated on a $1^{\circ} \times 1^{\circ}$ grid in the upper plot and at vertical steps of $10 \mathrm{hPa} \times 1^{\circ}$ in longitude in the bottom plot.
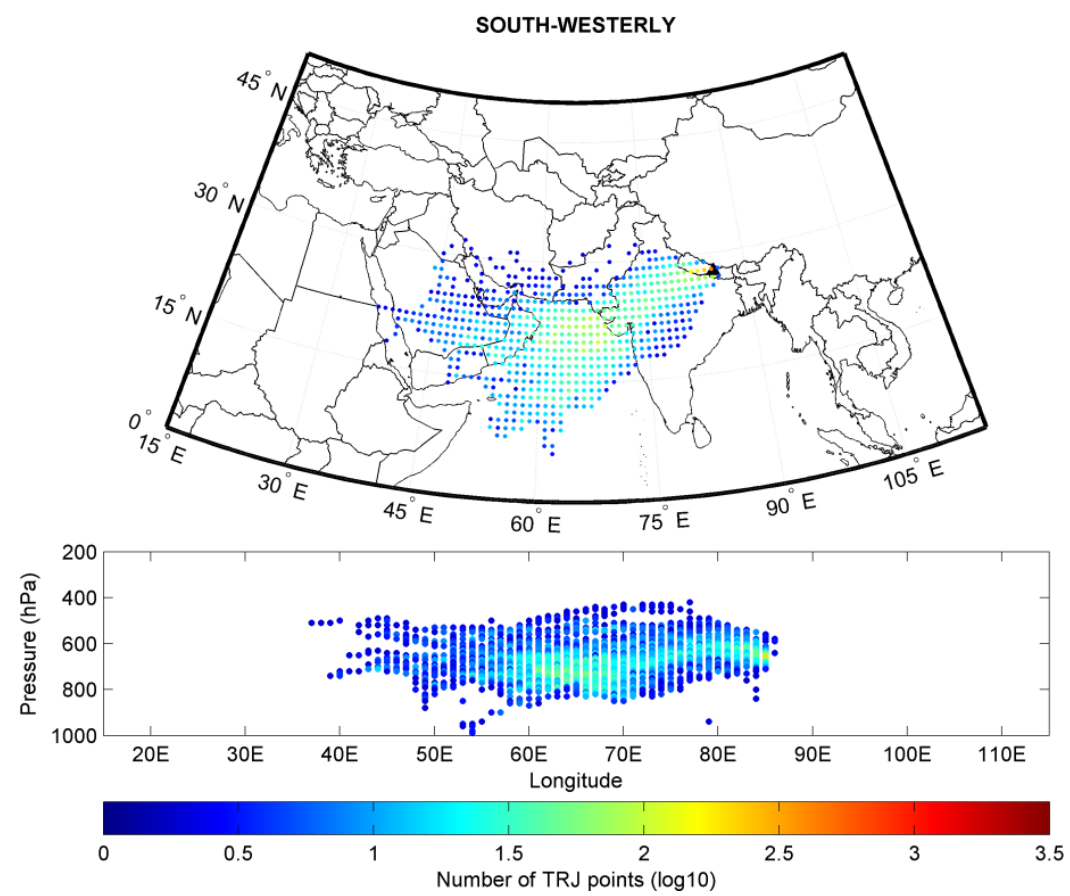

Figure S3. Same as Fig. S1, but for South-westerly cluster. 

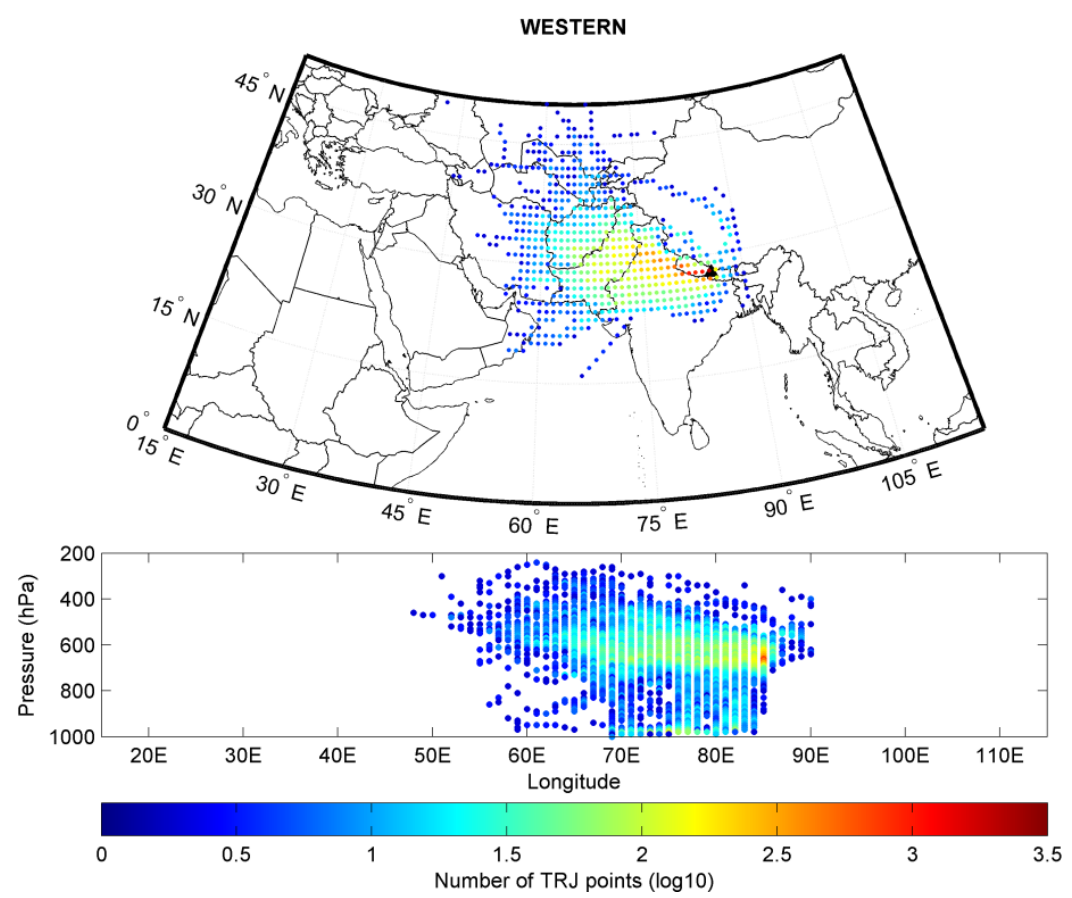

Figure S4. Same as Fig. S1, but for Western cluster.
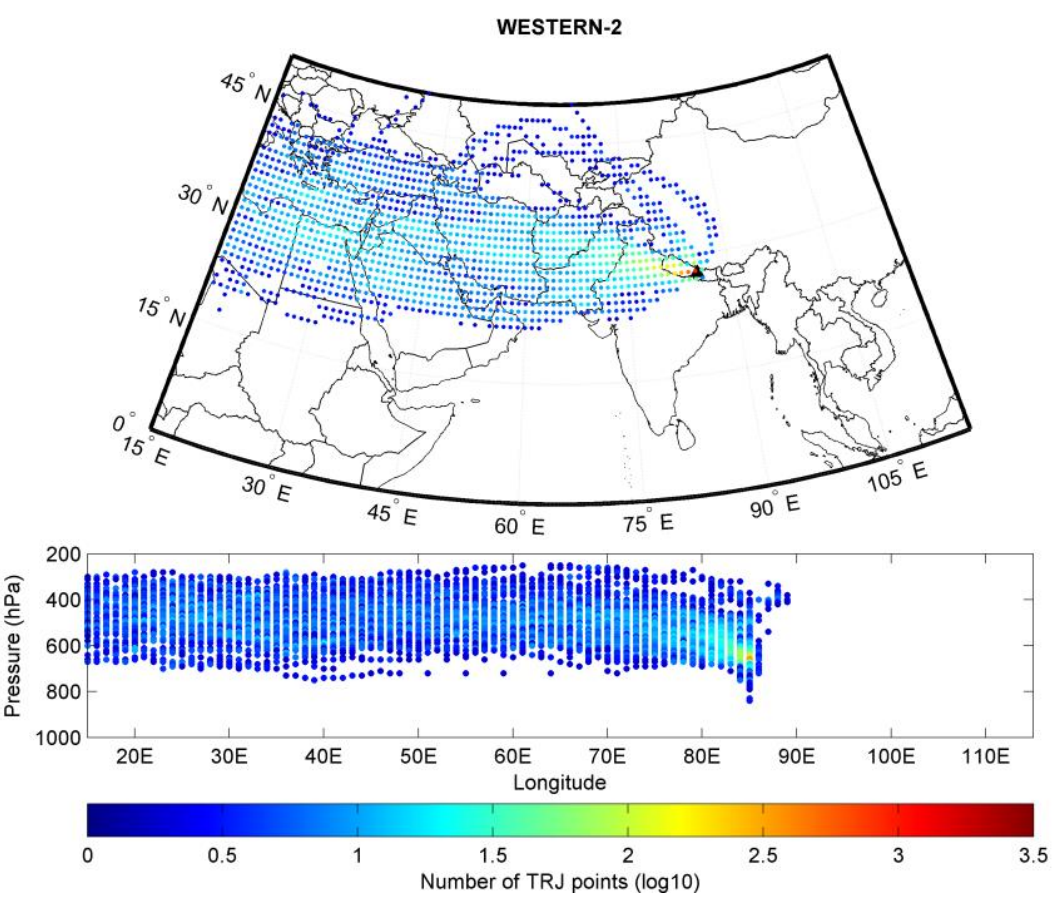

Figure S5. Same as Fig. S1, but for Western-2 cluster. 

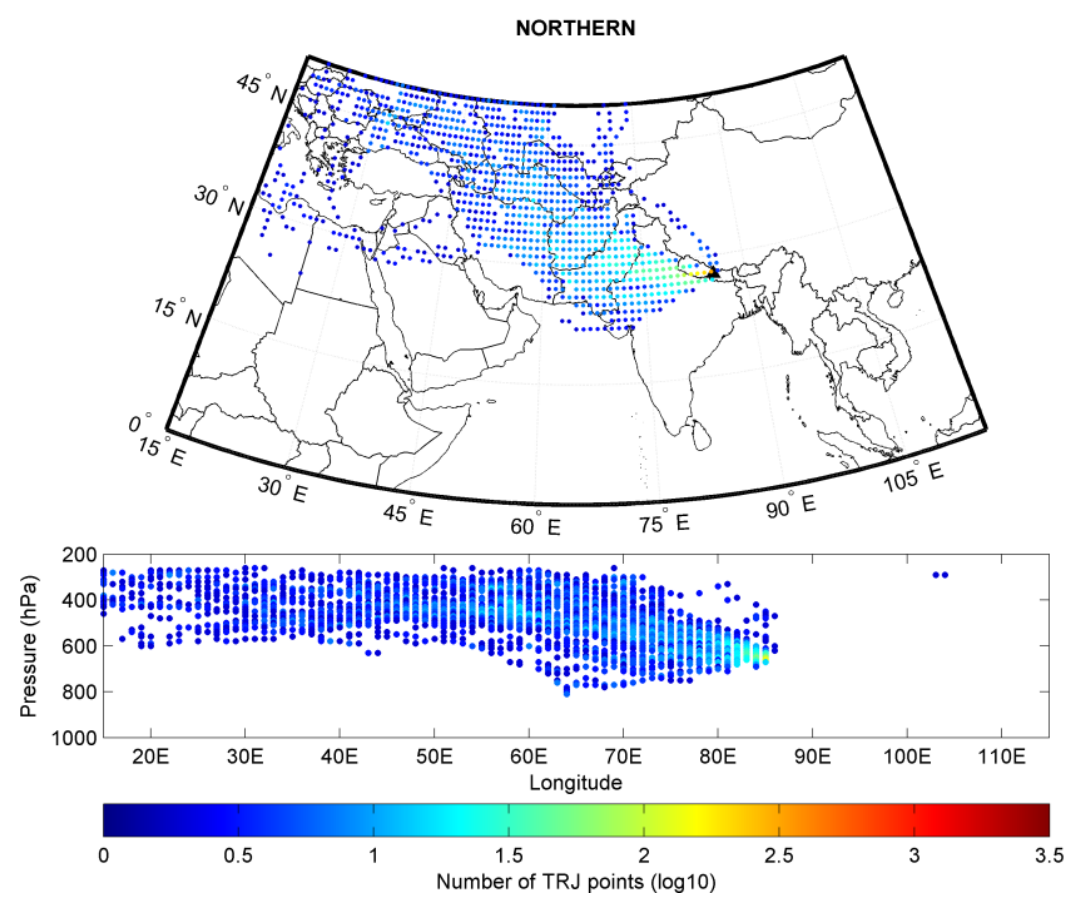

Figure S6. Same as Fig. S1, but for Northern cluster.
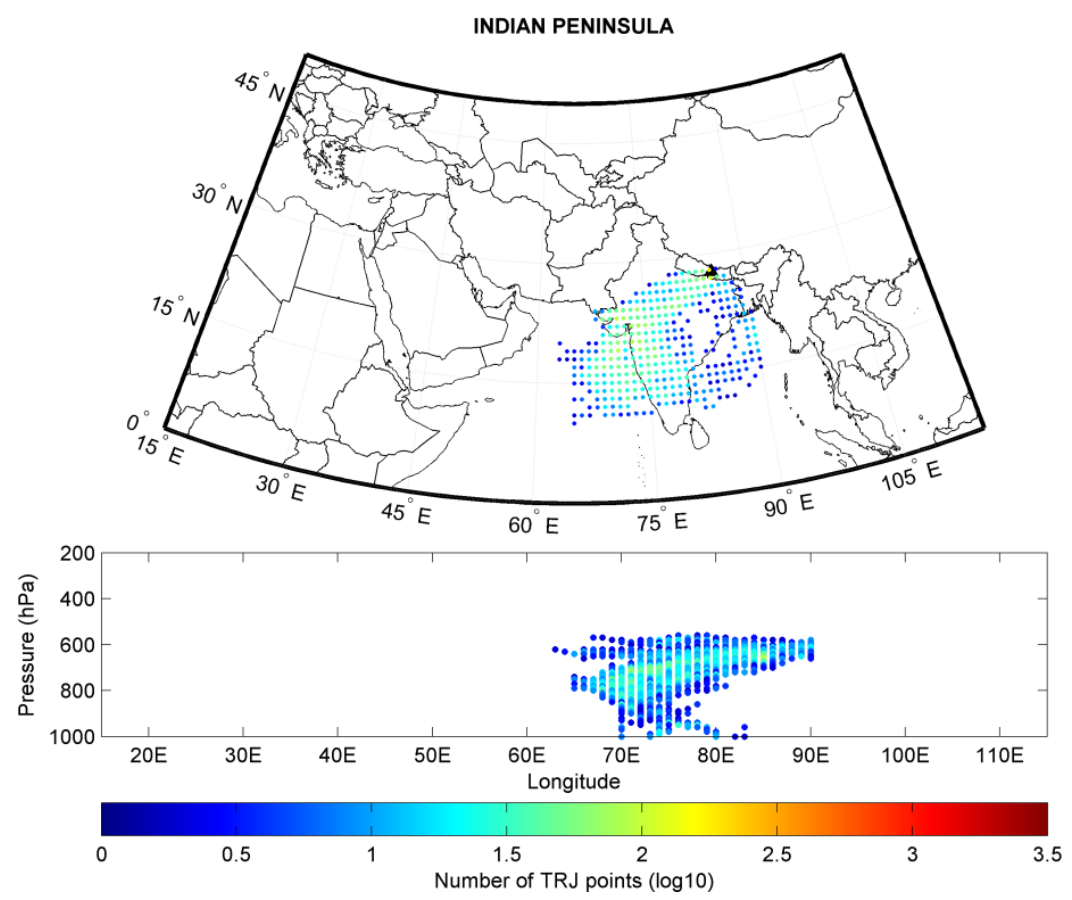

Figure S7. Same as Fig. S1, but for Indian Peninsula cluster. 


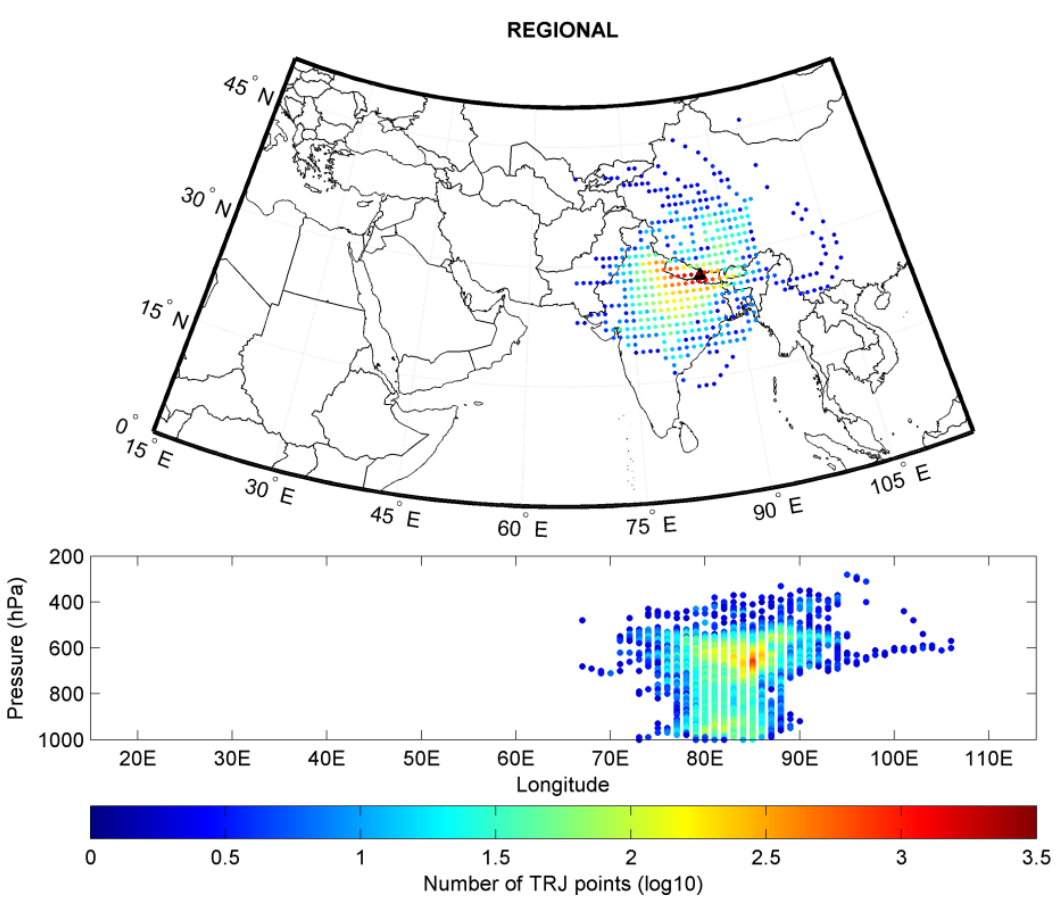

Figure S8. Same as Fig. S1, but for Regional cluster.

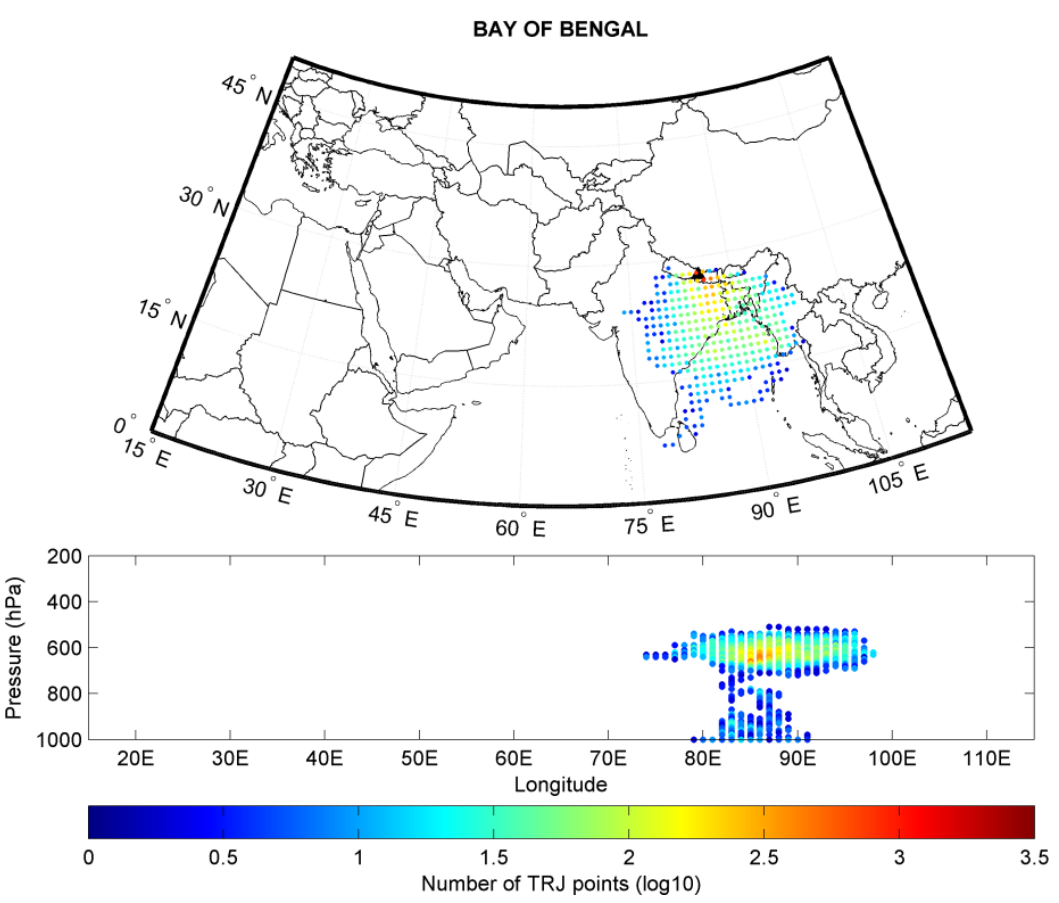

Figure S9. Same as Fig. S1, but for Bay of Bengal cluster. 


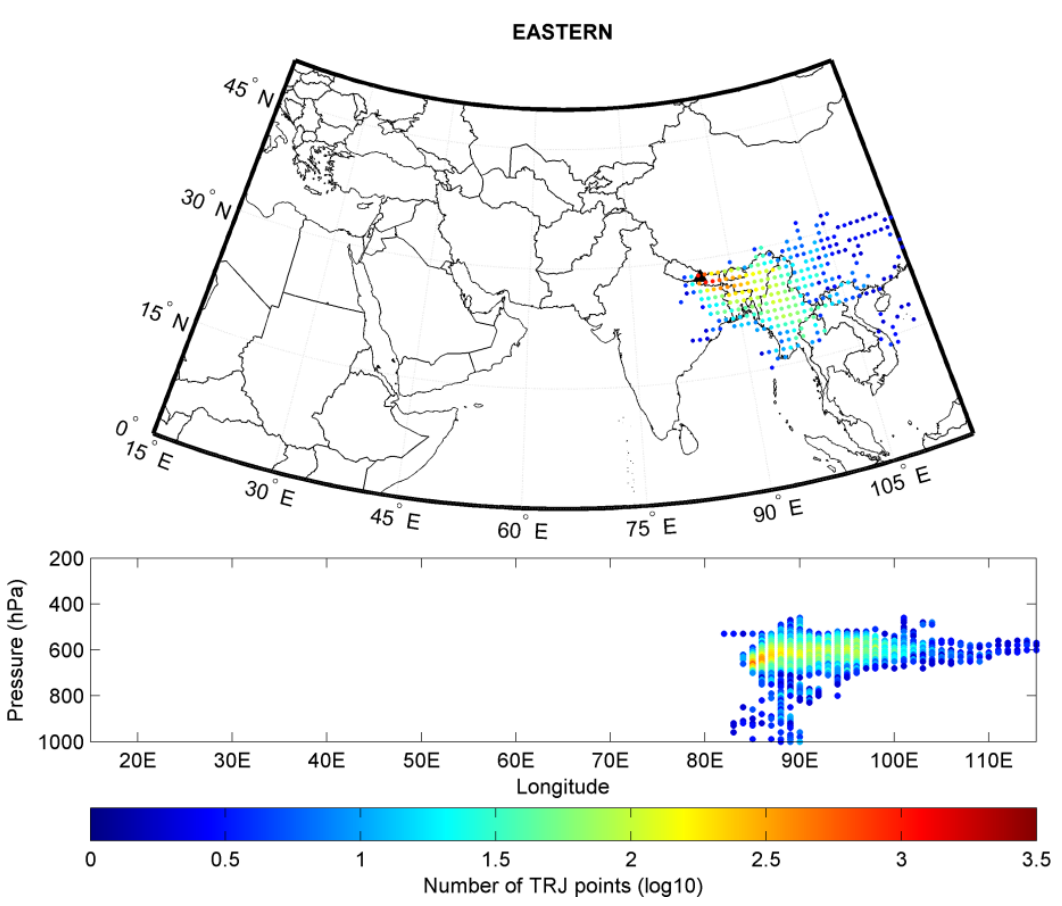

Figure S10. Same as Fig. S1, but for Eastern cluster. 